\title{
Progress in the understanding and treatment of chronic anal fissure
}

\author{
K McCallion, K R Gardiner
}

\begin{abstract}
Background-Chronic anal fissure is a common and painful condition associated with internal anal sphincter hypertonia. Reduction of this hypertonia improves the local blood supply, encouraging fissure healing. Surgical sphincterotomy is very successful at healing these fissures but requires an operation with associated morbidity. Temporary reduction in sphincter tone can be achieved on an outpatient basis by applying a topical nitric oxide donor (for example, glyceryl trinitrate) or injecting botulinum toxin into the anal sphincter.

Methods-A Medline database was used to perform a literature search for articles relating to the non-surgical treatment of chronic anal fissure.

Results-Review of the literature shows botulinum toxin injection to be more effective at healing chronic anal fissures than topical glyceryl trinitrate. Topical isosorbide dinitrate has not been directly compared with either of these two agents but has a healing rate approaching that of botulinum toxin injection. The main side effect of botulinum toxin injection is temporary faecal incontinence in approximately $2 \%$ of cases, whereas topical nitrates cause headaches in $20 \%-100 \%$ of cases. No long term side effects were identified with any of the medical treatments. Conclusion-Chemical sphincterotomy is an effective treatment for chronic anal fissure and has the advantages over surgical treatment of avoiding long term complications (notably incontinence) and not requiring hospitalisation.

(Postgrad Med F 2001;77:753-758)
\end{abstract}

Keywords: chronic anal fissure; sphincterotomy; glyceryl trinitrate; botulinum toxin

Anal fissure is a common condition causing severe pain during defecation. Until recently the "gold standard" treatment for chronic anal fissure was a surgical lateral internal sphincterotomy which, although effective at healing the fissure, has a definite risk of permanent faecal incontinence.

Recent advances in the understanding of the ischaemic nature of this disease have led to the use of two different types of temporary chemical sphincterotomy. The first involves the use of topical glyceryl trinitrate and the second an injection of botulinum toxin into the internal anal sphincter. Both are effective at healing the fissure and both produce only temporary sphincter hypotonia.

\section{Background}

An anal fissure is a split in the mucosa extending from the anal verge towards the dentate line. It was first recognised as a disease in $1934^{1}$ and currently affects $10 \%$ of patients attending proctology clinics. ${ }^{2}$ Fissures usually present with pain and small amounts of bright red rectal bleeding. Contrary to traditional teaching, a precipitating history of constipation is found only in a small percentage of patients (approximately $20 \%$ ).

Acute fissures usually heal with conservative management. Fissures lasting greater than two months with features of chronicity (Sentinel skin tag, hypertrophied anal papilla, exposure of the underlying internal anal sphincter or anal cicatrisation) are unlikely to heal with conservative management. Fissures due to an underlying disease (for example, perianal Crohn's disease where fissures are often multiple and situated laterally) are also unlikely to resolve with conservative management.

\section{Aetiology}

The internal anal sphincter hypertonia seen in patients with an anal fissure has long been thought to be a secondary phenomenon, occurring after local trauma to the mucosa by, for example, the passage of hard faeces. In this scenario, subsequent sphincter spasm then leads to further constipation and so a vicious cycle is created. Traditional treatment (anal dilatation and internal sphincterotomy) aims to break this cycle by disrupting the internal anal sphincter.

Recent research has shown the blood flow to the posterior midline of the anus to be potentially deficient, being supplied by end arteries (mean arteriolar blood pressure $85 \mathrm{~mm}$ $\mathrm{Hg}$ ) which pass through the internal anal sphincter before reaching the posterior commissure. $^{3}$ As the maximum resting anal pressure (MRAP) is usually greater than $90 \mathrm{~mm} \mathrm{Hg}$ in patients with fissures, ${ }^{4}$ such hypertonia will compress these end arteries and cause ischaemia of the posterior commissure. Such a reduction in the posterior anodermal blood flow has been confirmed using laser Doppler flowmetry. ${ }^{5}$ Further evidence that the hypertonia is not secondary to pain arises from the demonstration that it is not relieved by the use of topical anaesthetics. ${ }^{6}$

This evidence supports the hypothesis that anal fissures are caused by internal anal sphincter hypertonia producing ischaemia of the posterior commissure of the anus. This explains the presence of sphincter spasm, severe pain (ischaemic in nature), predilection for the posterior midline, and poor healing. It 
Table 1 Clinical trials of chemical sphincterotomy

\begin{tabular}{|c|c|c|c|c|c|c|c|}
\hline Reference & Treatment & Trial design & $\begin{array}{l}\text { No of } \\
\text { patients }\end{array}$ & Healing rate & $\begin{array}{l}\text { Incontinence rate } \\
\text { for flatus }(F) \text { or } \\
\text { stool }(S)\end{array}$ & Headache rate & Relapse rate \\
\hline $\begin{array}{l}\text { Lund and } \\
\text { Scholefield }^{33}\end{array}$ & $\begin{array}{l}0.2 \% \text { GTN } v \text { white soft } \\
\text { paraffin }\end{array}$ & PRCT & 80 & $68 \%$ at $8 w$ & $0 \%$ & $58 \% \star$ & $8 \%$ at $4 \mathrm{~m} \dagger$ \\
\hline Carapeti et $a l^{35}$ & $\begin{array}{l}0.2-0.6 \% \text { GTN } v \text { yellow } \\
\text { paraffin }\end{array}$ & PRCT & 70 & $\begin{array}{l}67 \% 2 \mathrm{w} \text { after } 8 \mathrm{w} \text { of } \\
\text { treatment }\end{array}$ & $\mathrm{F}: 13 \%$ & $72 \%$ & $29 \%$ at $6-14 \mathrm{~m} \ddagger$ \\
\hline Bacher et $a l^{37}$ & $0.2 \%$ GTN $v$ lignocaine gel & PRCT & 13 & $62 \%$ at $4 \mathrm{w}$ & $0 \%$ & $20 \%$, mild & $0 \%$ at $4 \mathrm{w}$ \\
\hline Lysy $e t a l^{41}$ & $1.25-2.5 \mathrm{mg}$ ISDN spray & Uncontrolled & 41 & $83 \%$ at $4 \mathrm{w}$ & - & $19.5 \% \star$ & $18 \%$ at $3-17 \mathrm{~m} \dagger$ \\
\hline Schouten $e t a l^{36}$ & $1 \%$ ISDN & Uncontrolled & 34 & $88 \%$ at $12 \mathrm{w}$ & $0 \%$ & $100 \%$, mild & $7 \%$ at $10 \mathrm{w}$ \\
\hline Maria et $a l^{44}$ & BoTx $20 \mathrm{U} v$ saline & PRCT & 30 & $\begin{array}{l}73 \% \text { at } 8 w, 100 \% \text { with } 2 \text { nd } \\
\text { dose }\end{array}$ & F: $4 \%$ & - & $0 \%$ at $16 \mathrm{~m}$ \\
\hline Jost $^{47}$ & BoTx 5-10U & Uncontrolled & 100 & $79 \%$ at $6 \mathrm{~m} \rrbracket$ & $\mathrm{F}: 7 \%, \mathrm{~S}: 2 \%$ & - & $8 \%$ at $6 \mathrm{~m}$ \\
\hline Mason et al $l^{49}$ & BoTx $0.125-1 \mathrm{ng}$ & Uncontrolled & 5 & $60 \%$ at $6 \mathrm{~m} \sqrt{ }$ & $0 \%$ & - & $0 \%$ at $6 \mathrm{~m}$ \\
\hline Cook $e t a P^{3}$ & $\begin{array}{l}\text { Nifedipine } 20 \mathrm{mg} \text { orally } \\
\text { twice daily }\end{array}$ & Uncontrolled & 15 & $60 \%$ at $8 w$ & $0 \%$ & $\begin{array}{l}27 \% \text {, mild }(67 \% \\
\text { flushing) }\end{array}$ & $7 \%$ at $1 \mathrm{~m}$ \\
\hline Brisinda et $a \bar{l}^{4}$ & $\begin{array}{l}\text { BoTx } 20 U v \\
0.2 \% \text { GTN twice daily for } \\
6 \mathrm{w}\end{array}$ & PRT & $\begin{array}{l}25 \\
25\end{array}$ & $\begin{array}{l}96 \% \text { at } 2 \mathrm{~m}^{\star \star} \\
60 \% \text { at } 2 \mathrm{~m}^{\star \star}\end{array}$ & $\begin{array}{l}0 \% \\
0 \%\end{array}$ & $\begin{array}{l}0 \% \\
20 \% \star\end{array}$ & $0 \%$ at $16 \mathrm{~m}$ \\
\hline
\end{tabular}

${ }^{\star}$ One patient discontinued treatment because of severe headaches.

†All successfully retreated.

$\ddagger 44 \%$ successfully retreated with GTN.

$\$$ No rescue treatment given.

ๆSuccessfully retreated with topical GTN.

$\star \star$ All patients successfully treated by crossing over to the alternative treatment.

GTN = glyceryl trinitrate, ISDN = isosorbide dinitrate, BoTx $=$ botulinum toxin, $\mathrm{PRCT}=$ prospective randomised control trial, $\mathrm{PRT}=$ prospective randomised trial, $\mathrm{m}=$ months, $\mathrm{w}=$ weeks.

also explains how surgery to disrupt the internal anal sphincter and improve anodermal blood flow allows the fissure to heal.

\section{Surgical sphincterotomy}

Although acute anal fissures usually respond to conservative management, lateral internal sphincterotomy has been the treatment of choice for chronic anal fissures. ${ }^{7}$ Sphincterotomy was first described in 1835 and can be carried out using an open or a subcutaneous ${ }^{8}$ technique and under local or general anaesthesia. Two large studies have demonstrated a $2.3 \%-3 \%$ failure rate at five years. ${ }^{910}$ The median time to fissure healing was 5.6 weeks, with incontinence for flatus occurring in $3 \%-36 \%$, soiling in $4.4 \%-21 \%$, and faecal incontinence in $0.4 \%-4.9 \%$. The extent of sphincterotomy may influence the subsequent outcome (in terms of healing and incontinence) and it would appear reasonable to divide the sphincter for the length of the fissure. ${ }^{112}$ It has been suggested that open sphincterotomies are longer than closed ones, ${ }^{12}$ explaining why they have been shown to have a higher risk of incontinence than the closed technique. ${ }^{13}$ Various studies have shown lateral internal sphincterotomy to be superior to anal dilatation and posterior internal sphincterotomy. ${ }^{14}{ }^{15}$ Posterior internal sphincterotomy results in a keyhole deformity of the anal canal and a wound which is slow to heal, presumably because of the inadequate blood supply.

\section{Anal dilatation}

Anal dilatation was first described in $1838^{16}$ and was popularised by Lord in the treatment of haemorrhoids. ${ }^{17}$ Lord's original eight finger dilatation was abandoned in favour of a more gentle four finger stretch for four minutes ${ }^{18}$ and more recently a standardised dilatation procedure using a Parks' retractor opened to $4.8 \mathrm{~cm}$ or with a $40 \mathrm{~mm}$ rectosigmoid balloon has been advocated in the treatment of chronic anal fissures. ${ }^{19}$ Although anal dilatation results in successful healing of anal fissures comparable to lateral internal sphincterotomy, ${ }^{20-24}$ there is no way to reliably standardise the procedure and both the internal and external sphincters can be disrupted or fragmented in an irregular manner. ${ }^{25}{ }^{26}$ Nielsen et al have used postoperative endoanal ultrasound to show that sphincter damage occurs in $65 \%$ of patients undergoing anal dilatation with minor anal incontinence occurring in $12.5 \%$ of cases. ${ }^{26}$ Retrospective $^{27}$ and prospective ${ }^{1422}$ trials have shown that anal dilatation has a higher risk of incontinence than that of lateral internal sphincterotomy. Saad and Omer demonstrated anal incontinence in $4.8 \%$ of patients undergoing lateral internal sphincterotomy $(1 / 21)$ but in $24.3 \%(9 / 37)$ of patients after anal dilatation, ${ }^{22}$ although some authors still support a policy of gentle anal dilatation as the treatment of choice in chronic anal fissure..$^{23}$

\section{Chemical sphincterotomy-nitric oxide donor}

The mediator of the non-adrenergic noncholinergic pathway stimulating relaxation of the internal sphincter has been shown to be nitric oxide. ${ }^{28-30}$ Application of topical nitric oxide donors has been shown to reduce anal pressure. ${ }^{31}{ }^{32}$ Such observations have generated an interest in the use of nitric oxide donors as a form of chemical sphincterotomy (table 1).

A prospective, randomised, double blind, placebo controlled trial in 80 recruited patients with chronic anal fissures revealed a $68 \%$ (26/38 cases) healing rate at eight weeks when $0.2 \%$ glyceryl trinitrate ointment was applied twice daily compared with an $8 \%$ (3/39 cases) healing rate for placebo. ${ }^{33}$ Healing correlated with a reduction in pain, reduced MRAP, and an improvement in anodermal blood flow. There was an $8 \%$ relapse rate at four months but these three patients were successfully retreated with glyceryl trinitrate ointment and no further relapse had been recorded four months later. Long term results are awaited. The median time to healing was six weeks, with $58 \%$ of patients developing headaches and one 
patient $(2.6 \%)$ required surgery after stopping the treatment for this reason. There were no cases of incontinence. The MRAP has been shown to return to pre-treatment levels once the glyceryl trinitrate has been stopped. ${ }^{34}$

A more recent prospective, randomised, double blind, placebo controlled trial in 70 patients with chronic anal fissures revealed a $65 \%$ (15/23 cases) healing rate at two weeks after an eight week course of $0.2 \%$ glyceryl trinitrate ointment applied three times a day compared to $32 \%$ ( $7 / 22$ cases) for placebo. ${ }^{35}$ The median time to healing was eight weeks. Increasing the strength of glyceryl trinitrate ointment to a maximum of $0.6 \%$ did not improve healing efficacy $(16 / 23,70 \%)$. Glyceryl trinitrate treatment caused a significantly bigger reduction in MRAP compared with the placebo group but this was not associated with an improvement in anodermal blood flow. During a median follow up of nine months, symptomatic recurrence rates were $43 \%$ for the placebo group (3/7), 33\% for the $0.2 \%$ glyceryl trinitrate group (5/15), and $25 \%$ for the higher dose glyceryl trinitrate group (4/16). Forty four per cent of these recurrences were successfully treated with a second course of glyceryl trinitrate. Seventy two per cent of patients receiving glyceryl trinitrate developed headaches, with no difference between the low and high dose groups (15/23 $v$ 18/23 respectively). Temporary loss of flatus control was observed in 6/46 patients during glyceryl trinitrate treatment, with no case of faecal incontinence. This study therefore reports higher rates of side effects (headache and temporary loss of flatus control) and higher recurrence rates than that of Lund et al above. ${ }^{34}$ Also, although glyceryl trinitrate application caused fissure healing and a reduction in MRAP, there was no measurable increase in anodermal blood flow observed after eight weeks in this study. This is contrary to the hypothesis that glyceryl trinitrate heals fissures by improving blood flow to an essentially ischaemic ulcer and in contrast to other studies which have documented improved anodermal blood flow with the use of topical nitric oxide donors. ${ }^{33}{ }^{36}$ Carapeti et al assumed that their unexpected finding of no increase in anodermal blood flow was due to homoeostatic mechanisms responsible for regulation of cutaneous blood flow compensating for the vasodilatory effect of glyceryl trinitrate..$^{35}$

A smaller prospective, randomised, controlled trial using $0.2 \%$ glyceryl trinitrate ointment applied three times a day produced a one month healing rate of $62.5 \%$ (five of eight patients with chronic anal fissure) compared with $20 \%$ (one of five patients) when $2 \%$ lignocaine was used. ${ }^{37}$ Of interest, the MRAP was not significantly lowered during the one month study period in four of the five patients successfully treated by glyceryl trinitrate. Of a total of 20 patients treated with glyceryl trinitrate (12 acute and eight chronic fissures), $20 \%$ suffered mild headache and there was no report of incontinence. The one month healing rate for acute anal fissures was also significantly improved (91.6\% with glyceryl trinitrate $v 50 \%$ with lignocaine).

It has been suggested that tachyphylaxis may occur when glyceryl trinitrate is used to treat anal fissure, ${ }^{38}$ just as it occurs in cardiovascular disease. Higher doses may overcome this problem as there is some evidence that the internal anal sphincter demonstrates a dose related response to the application of glyceryl trinitrate. ${ }^{39}$

A potential problem with using glyceryl trinitrate ointment outside of a trial setting may be poor compliance. A retrospective mail audit of 27 patients who were prescribed glyceryl trinitrate ointment $0.2 \%$ twice daily reported a compliance rate of $67 \%$ with a healing rate of only $56 \%$ after three to 10 weeks of treatment. ${ }^{40}$

An uncontrolled prospective observational study looked at the use of isosorbide dinitrate spray in the treatment of anal fissures. ${ }^{41}$ In 41 patients studied, symptoms had been present for two to 120 months with classical signs of chronicity present in only $61 \%$ of cases. All the patients had failed to heal after three weeks of conservative management. In this group of patients, isosorbide dinitrate 1.25 or $2.5 \mathrm{mg}$ (one or two sprays) applied three times a day for four weeks produced healing in $83 \%$ $(34 / 41)$ of patients at four months. A second four week course of isosorbide dinitrate produced healing in one more patient. There was an $18 \%$ relapse rate $(6 / 34)$ after a mean follow up of 11 months, all of which were successfully retreated with a further four week course of isosorbide dinitrate. Patients with an anal fissure of long duration were more likely to relapse than those of shorter duration, showing the importance of such factors when comparing different studies. During the follow up, a further $12 \%(4 / 34)$ of patients developed mild symptoms which were successfully treated with the use of isosorbide dinitrate for not more than four days. There was a significantly greater reduction in MRAP in those patients where the anal fissure was healed compared to those where treatment failed. Headaches occurred in $19.5 \%$ of patients, with one patient discontinuing treatment due to severe headaches. Higher doses ( $3.75 \mathrm{mg}$ or $5 \mathrm{mg}$ ) of isosorbide dinitrate resulted in headaches in approximately $40 \%$ of cases (6/15 and $4 / 9$ respectively). There was no mention of incontinence.

An uncontrolled study using topical $1 \%$ isosorbide dinitrate applied five times a day in 34 patients produced similar results with a healing rate of $88 \%$ (30/34 cases) at 12 weeks. ${ }^{36}$ There was a $7 \%(2 / 30$ cases $)$ relapse rate at 10 weeks and no further relapse at a mean follow up of 11 months. Six of the 34 patients studied underwent ambulant anal manometry. This revealed that during sleep the anal pressure falls to $39 \%$ of ambulatory values. Nitrate ointment therefore only needs to be applied during the day.

\section{Chemical sphincterotomy-botulinum toxin}

Botulinum toxin, a neurotoxin released from Clostridium botulinum, prevents the release of acetylcholine from presynaptic axon terminals. 
Its action is short lived and full recovery of the synapse is expected within 12 weeks. It is used to treat skeletal muscle disorders including blepharospasm and spasticity associated with cerebral palsy. It is also being evaluated in smooth muscle disorders including achalasia and anismus. ${ }^{42}$ Its use in chronic anal fissure was reported in 1993 (table 1). ${ }^{43}$ By causing temporary synaptic blockade, botulinum toxin has been shown to relax the internal anal sphincter when injected into $\mathrm{it}^{44}$ or into the external anal sphincter. ${ }^{45}$ By contrast, botulinum toxin injected into the internal anal sphincter has no effect on the external anal sphincter. ${ }^{44}$ As the external anal sphincter is not involved in the pathogenesis of anal fissures and may be voluntarily contracted to maintain continence, it makes theoretical sense to avoid paralysing the external anal sphincter if possible. There is evidence that at least 15 units of botulinum toxin A must be injected in order to produce a significant decrease in the MRAP. ${ }^{46}$

A prospective, randomised, double blind, placebo controlled trial in 30 patients with chronic anal fissures revealed a $73 \%(11 / 15$ cases) healing rate at two months using botulinum toxin A (20 units injected as two 10 unit aliquots into the internal anal sphincter on either side of the fissure) compared with a $13 \%$ $(2 / 15$ cases) healing rate when saline was injected. ${ }^{44}$ The remaining $27 \%$ in the treatment group were healed two months later after a further injection of 25 units of botulinum. However, three of 10 patients in the control group who crossed over to botulinum injection at two months dropped out of the study and were treated surgically (giving a 70\% successful healing rate in this subgroup). Healing correlated with a reduction in pain and MRAP. There were no relapses at 16 months. One case of temporary flatus incontinence was reported out of 25 patients who received botulinum toxin (that is $4 \%$ ).

Similar results have also been reported in an uncontrolled study $(n=100)$ after the injection of botulinum toxin into the external anal sphincter (two aliquots each of 2.5 or 5 unitsdepending on sphincter strength - injected into either side of the fissure) ${ }^{47}$ In this study there was no rescue treatment given for those fissures failing to heal. The healing rate was $79 \%$ at six months (excluding eight patients who had relapsed within this time), with seven cases of temporary flatus incontinence lasting less than two weeks and two cases of temporary faecal incontinence lasting less than one week. In a subsequent study, 20 patients with recurring chronic anal fissures after initial successful treatment with 5 units of botulinum toxin were given a second dose ( 5 units), resulting in a $70 \%(14 / 20)$ healing rate at three months. ${ }^{48}$ No side effects were observed. This study also investigated the use of a second dose of botulinum toxin (10 units) in 30 patients with chronic anal fissures who had failed to heal after initial treatment with 5 units. The healing rate in this group was $63.3 \%(19 / 30)$ at three months, with transient faecal incontinence observed in $6.7 \%(2 / 30)$ patients.
A smaller study demonstrated a $60 \%(3 / 5$ cases) healing rate in five patients with chronic anal fissures after injection of the internal anal sphincter with a total of $0.125 \mathrm{ng}$ or $0.25 \mathrm{ng}$ or $1 \mathrm{ng}$ of botulinum toxin $\mathrm{A}$ into one or two sites. $^{49}$

\section{Chemical sphincterotomy-calcium antagonists}

Calcium channel blockers reduce the contractility of cardiac and smooth muscle myocytes by inhibiting the cellular influx of calcium ions. Consequently, drugs such as nifedipine and diltiazem have been used in the treatment of oesophageal dysmotility with varying degrees of success. Serendipitously, oral diltiazem 80 mg twice daily was noticed to produce immediate relieve of proctalgia fugax in a 44 year old woman being treated for Raynaud's disease..$^{50}$ The proctalgia immediately recurred when the diltiazem was discontinued during warmer weather. Diltiazem $60 \mathrm{mg}$ orally $^{5152}$ and $2 \%$ gel topically ${ }^{52}$ have been shown to reduce the MRAP by $21 \%$ and $28 \%$ respectively in healthy volunteers. Whereas oral diltiazem caused postural dizziness in $20 \%$ of cases, topical diltiazem caused no side effects. ${ }^{52}$

A large prospective, randomised, double blind, controlled multicentre trial in 283 patients compared $0.2 \%$ nifedipine gel twice daily for three weeks with $1 \%$ lidocaine $+1 \%$ hydrocortisone acetate gel twice daily for three weeks in the treatment of acute anal fissures. Both groups of patients also used anal dilators. After four weeks, $98 \%$ of the nifedipine group were healed compared with $61 \%$ of the control group. By six weeks, $74 \%$ of the control group were healed; $2 \%(3 / 141)$ of the nifedipine group and $26 \%(37 / 142)$ of the control group subsequently underwent surgical sphincterotomy. No systemic side effects were noted in the nifedipine group. The use of topical nifedipine was noted to reduce MRAP by $30 \%$ and maximum squeeze pressure by $16.8 \%$.

An uncontrolled study in 15 patients with chronic anal fissures investigated the use of oral nifedipine $20 \mathrm{mg}$ twice daily. ${ }^{53}$ After eight weeks, healing was complete in $60 \%(9 / 15)$ and a further $20 \%$ (3/15) were asymptomatic and declined further treatment. One patient withdrew from the study within 24 hours of entering for reasons apparently not related to the treatment. Of the two patients with treatment failure remaining in the study, one was successfully treated with glyceryl trinitrate paste and one underwent surgical sphincterotomy. There was one recurrence in the first month which responded to topical glyceryl trinitrate. Side effects included mild headache (4/15), flushing (10/15), and mild ankle oedema (1/15). All side effects were in the first four weeks of treatment. There were no episodes of incontinence. The first dose of nifedipine caused a $36 \%$ reduction in MRAP with no change in maximum squeeze pressure.

\section{Botulinum toxin versus topical glyceryl} trinitrate

The choice of conservative treatment for chronic anal fissure was clarified by Brisinda et 
al when they prospectively randomised 50 patients to receive botulinum toxin (20 units given as two injections to both sides of the internal anal sphincter, $n=25$ ) or $0.2 \%$ glyceryl trinitrate ointment applied twice daily for six weeks. ${ }^{54}$ At two months, the healing rate was significantly higher in the botulinum toxin group compared to the glyceryl trinitrate group (96\% $v 60 \%$ respectively). Healing was also significantly quicker in the botulinum toxin group ( $88 \%$ v $40 \%$ respectively at one month). Twenty per cent $(5 / 25)$ of patients in the glyceryl trinitrate group developed headaches, causing one patient to leave the study and undergo surgical sphincterotomy. There were no adverse side effects in the botulinum toxin group. Apart from the one patient who underwent surgical sphincterotomy after severe headaches while using glyceryl trinitrate, the remaining failures were successfully treated after crossing over to the other treatment. There were no relapses after an average follow up of 15 months. Botulinum toxin was noted to reduce the MRAP significantly more than glyceryl trinitrate. Furthermore, in the glyceryl trinitrate group, MRAP was reduced in the 15 success cases but not in the nine failures. The MRAP in the latter group was however reduced after successful treatment with botulinum toxin. This emphasises the importance of reducing internal anal sphincter hypertonia during the medical management of chronic anal fissure. Maximal squeeze pressure was not affected by either botulinum toxin or glyceryl trinitrate, explaining the absence of incontinence as a side effect in this study.

Although this study revealed no adverse effects with the use of botulinum toxin in the treatment of chronic anal fissures, experience with its use elsewhere has identified potential side effects including generalised muscle weakness (mild botulism), ${ }^{55}$ necrotising fasciitis, ${ }^{56}$ possible reduced sensitivity to vecuronium, ${ }^{57}$ and the development of antibodies depending on the type of toxin used..$^{58}$ However, the most likely adverse effect in the treatment of chronic anal fissure is temporary incontinence, especially for flatus. ${ }^{44}$

\section{Conclusions}

Despite surgery's effective healing of chronic anal fissures, chemical sphincterotomy has the advantages of avoiding long term complications (notably incontinence) and not requiring hospitalisation. Botulinum toxin injection has the advantage of an excellent healing rate, can be repeated if necessary and abolishes the need for patient compliance. It is however expensive and temporary incontinence has been reported with its use. Topical glyceryl trinitrate is cheap, has a good healing rate, and faecal incontinence has not been reported. Its effectiveness, however, depends on patient compliance which may be poor in view of associated headaches and a local burning sensation. Long term follow up is not available on chemical sphincterotomy and therefore the risk of recurrent anal fissure in the future is unknown.

As topical glyceryl trinitrate is simple to apply, achieves satisfactory healing rates and is cheap, the authors recommend this as the first line treatment for chronic anal fissures as it could be prescribed by the general practitioner in the absence of any additional anal pathology. The majority of patients will therefore receive appropriate treatment without waiting to be seen at a surgical outpatient clinic. Patients unresponsive to topical glyceryl trinitrate could then be referred for outpatient botulinum toxin injection followed, in a small number of cases, by lateral internal sphincterotomy for those cases resistant to chemical sphincterotomy.

1 Lockhart Mummery JP. Diseases of the rectum and colon and their surgical treatment. Toronto: MacMillan, 1934.

2 Pescatori M, Interisano A. Annual report of the Italian coloproctology units. Tech Coloproctol 1995;3:29-30.

3 Klosterhalfen B, Vogel P, Rixen H, et al. Topography of the inferior rectal artery: a possible cause of chronic, primary anal fissure. Dis Colon Rectum 1989;32:43-52.

4 Prohm P, Bonner C. Is manometry essential for surgery of chronic fissure-in-ano? Dis Colon Rectum 1995;38:735-8.

5 Schouten WR, Briel JW, Auwerda JJ. Relationship between anal pressure and anodermal blood flow. The vascular pathogenesis of anal fissures. Dis Colon Rectum 1994;37: pathogene.

6 Minguez M, Tomas-Ridocci M, Garcia A, et al. Pressure of the anal canal in patients with haemorrhoids or with anal fissure. Effect of the topical application of an anaesthetic gel. Rev Esp Enferm Dig 1992;81:103-107.

7 Rosen L, Abel ME, Gordon PH, et al. Practice parameters for the management of anal fissure. The Standards Task Force American Society of Colon and Rectal Surgeons. Dis Colon Rectum 1992;35:206-8.

8 Notaras MJ. Lateral subcutaneous sphincterotomy for anal fissure-a new technique. Proc R Soc Med 1969;62:713.

9 Khubchandani IT, Reed JF. Sequelae of internal sphincterotomy for chronic fissure in ano. Br ₹ Surg 1989;76:431-4.

10 Pernikoff BJ, Eisenstat TE, Rubin RJ, et al. Reappraisal of partial lateral internal sphincterotomy. Dis Colon Rectum 1994;37:1291-5.

11 Sultan AH, Kamm MA, Nicholls RJ, et al. Prospective study of the extent of internal anal sphincter division during lateral of the extent of internal anal sphincter division durin
sphincterotomy. Dis Colon Rectum 1994;37:1031-3.

12 Garcia-Aguilar J, Belmonte Montes C, Perez JJ, et al. Incontinence after lateral internal sphincterotomy: anatomic and functional evaluation [see comments]. Dis Colon Rectum 1998;41:423-7.

13 Garcia-Aguilar J, Belmonte C, Wong WD, et al. Open vs closed sphincterotomy for chronic anal fissure: long-term results. Dis Colon Rectum 1996;39:440-3.

14 Jensen SL, Lund F, Nielsen OV, et al. Lateral subcutaneous sphincterotomy versus anal dilatation in the treatment of fissure in ano in outpatients: a prospective randomised study. BMf 1984;289:528-30.

15 Abcarian H. Surgical correction of chronic anal fissure: results of lateral internal sphincterotomy vs fissurectomymidline sphincterotomy. Dis Colon Rectum 1980;23:31-6.

16 Classic articles in colonic and rectal surgery. Stretching, massage and rhythmic percussion in the treatment of massage and rhythmic percussion in the treatment of
muscular contractions: Joseph-Claude-Anthelme Recamier (1774-1852). Dis Colon Rectum 1980;23:362-7.

17 Lord PH. A new regime for the treatment of haemorrhoids. Lord PH. A new regime for the
Proc R Soc Med 1968;61:935-6.

18 Weaver RM, Ambrose NS, Alexander-Williams J, et al. Manual dilatation of the anus vs lateral subcutaneous sphincterotomy in the treatment of chronic fissure-in-ano. Results of a prospective, randomized, clinical trial. Dis Colon Rectum 1987;30:420-3.

19 Sohn N, Eisenberg MM, Weinstein MA, et al. Precise anorectal sphincter dilatation-its role in the therapy of anal fissures. Dis Colon Rectum 1992;35:322-7.

20 Marby M, Alexander-Williams J, Buchmann P, et al. A randomized controlled trial to compare anal dilatation with lateral subcutaneous sphincterotomy for anal fissure. Dis Colon Rectum 1979;22:308-11.

21 Giebel GD, Horch R. Treatment of anal fissure: a comparison of three different forms of therapy. Nippon Geka Hokan 1989;58:126-33.

22 Saad AM, Omer A. Surgical treatment of chronic fissure-inano: a prospective randomised study. East Afr Med F 1992; 69:613-5.

23 Isbister WH, Prasad J. Fissure in ano. Aust N Z F Surg 1995; 65:107-8.

24 Oliver DW, Booth MW, Kernick VF, et al. Patient satisfaction and symptom relief after anal dilatation. Int $\mathcal{F}$ Colorectal Dis 1998;13:228-31.

25 Speakman CT, Burnett SJ, Kamm MA, et al. Sphincter injury after anal dilatation demonstrated by anal endosonography. Br f Surg 1991;78:1429-30

26 Nielsen MB, Rasmussen OO, Pedersen JF, et al. Risk of sphincter damage and anal incontinence after anal dilatation for fissure-in-ano. An endosonographic study. Dis Colon Rectum 1993;36:677-80.

27 Collopy B, Ryan P. Comparison of lateral subcutaneous Collopy B, Ryan P. Comparison of lateral subcutaneous
sphincterotomy with anal dilatation in the treatment of sphincterotomy with anal dilatation in the
fissure in ano. Med $\mathcal{F}$ Aust 1979;ii:461-2, 487 . 
28 Rattan S, Sarkar A, Chakder S. Nitric oxide pathway in rectoanal inhibitory reflex of opossum internal anal sphincter. toanal inhibitory reflex of opossu
Gastroenterology 1992;103:43-50.

29 O'Kelly T, Brading A, Mortensen N. Nerve mediated relaxation of the human internal anal sphincter: the role of nitric oxide. Gut 1993;34:689-93.

30 Stebbing JF. Nitric oxide synthase neurones and neuromuscular behaviour of the anorectum. Ann R Coll Surg Engl 1998;80:137-45.

31 Loder PB, Kamm MA, Nicholls RJ, et al. "Reversible chemical sphincterotomy" by local application of glyceryl trinitrate. Br F Surg 1994;81:1386-9.

32 Guillemot F, Leroi H, Lone YC, et al. Action of in situ nitroglycerin on upper anal canal pressure of patients with terminal constipation. A pilot study. Dis Colon Rectum 1993 36:372-6.

33 Lund JN, Scholefield JH. A randomised, prospective, double-blind, placebo-controlled trial of glyceryl trinitrate ointment in treatment of anal fissure [see comments] [pub-
lished erratum appears in Lancet 1997;349:656]. Lancet lished erratum

34 Lund JN, Parsons SL, Scholefield JH. Spasm of the internal anal sphincter in anal fissure-cause or effect? [abstract]. Gastroenterology 1996;110:A711.

35 Carapeti EA, Kamm MA, McDonald PJ, et al. Randomised controlled trial shows that glyceryl trinitrate heals anal fissures, higher doses are not more effective, and there is a high recurrence rate. Gut 1999;44:727-30.

36 Schouten WR, Briel JW, Boerma MO, et al. Pathophysiological aspects and clinical outcome of intra-anal application of isosorbide dinitrate in patients with chronic anal fissure. Gut 1996;39:465-9.

37 Bacher H, Mischinger HJ, Werkgartner G, et al. Local nitroglycerin for treatment of anal fissures: an alternative to
lateral sphincterotomy? Dis Colon Rectum 1997;40:840-5.

38 Watson SJ, Kamm MA, Nicholls RJ, et al. Topical glyceryl trinitrate in the treatment of chronic anal fissure. BrF Surg 1996;83:771-5.

39 Gunn J, Varma A, Monson J, et al. The dose response of the internal anal sphincter to topical application of glyceryl
trinitrate cream [abstract]. Dis Colon Rectum $1998 ; 41$.

40 Dorfman G, Levitt M, Platell C. Treatment of chronic anal fissure with topical glyceryl trinitrate. Dis Colon Rectum 1999;42:1007-10.

41 Lysy J, Israelit-Yatzkan Y, Sestiere-Ittah M, et al. Treatment of chronic anal fissure with isosorbide dinitrate: long-term results and dose determination. Dis Colon Rectum 1998;41: 1406-10.

42 Hallan RI, Williams NS, Melling J, et al. Treatment of anismus in intractable constipation with botulinum A toxin Lancet 1988;ii: 714-7.

43 Jost WH, Schimrigk K. Use of botulinum toxin in anal fissure [letter]. Dis Colon Rectum 1993;36:974.
44 Maria G, Cassetta E, Gui D, et al. A comparison of botulinum toxin and saline for the treatment of chronic anal fissure [see comments]. $N$ Engl f Med 1998;338:217-20.

45 Jost WH, Schimrigk K. Therapy of anal fissure using botulin toxin [see comments]. Dis Colon Rectum 1994;37:1321-

46 Espi A, Melo F, Minguez M, et al. Therapeutic effects of different doses of botulinum toxin in chronic anal fissure [abstract]. Dis Colon Rectum 1998;41:A16.

47 Jost WH. One hundred cases of anal fissure treated with botulin toxin: early and long-term results [see comments]. Dis Colon Rectum 1997;40:1029-32.

48 Jost WH, Schrank B. Repeat botulin toxin injections in anal fissure: in patients with relapse and after insufficient effect of first treatment. Dig Dis Sci 1999;44:1588-9.

49 Mason PF, Watkins MJ, Hall HS, et al. The management of chronic fissure in-ano with botulinum toxin [see comments]. F R Coll Surg Edinb 1996;41:235-8.

50 Boquet J, Moore N, Lhuintre JP, et al. Diltiazem for proctalgia fugax [letter]. Lancet 1986;i:1493.

51 Jonard P, Essamri B. Diltiazem and internal anal sphincter [letter]. Lancet 1987;i:754.

52 Carapeti EA, Kamm MA, Evans BK, et al. Diltiazem lowers resting anal sphincter pressure. A potential low side-effect alternative to glyceryl trinitrate (GTN) for fissures [abalternative to glyceryl trinitrate (G1)

53 Cook TA, Humphreys MM, Mortensen NJ. Oral nifedipine reduces resting anal pressure and heals chronic anal fissure. Br F Surg 1999;86:1269-73.

54 Brisinda G, Maria G, Bentivoglio AR, et al. A comparison of injections of botulinum toxin and topical nitroglycerin ointment for the treatment of chronic anal fissure [see comments]. N Engl f Med 1999;341:65-9.

55 Bhatia KP, Munchau A, Thompson PD, et al. Generalised muscular weakness after botulinum toxin injections for dystonia: a report of three cases. $\mathcal{F}$ Neurol Neurosurg Psychiatry 1999;67:90-3.

56 Latimer PR, Hodgkins PR, Vakalis AN, et al. Necrotising fasciitis as a complication of botulinum toxin injection. Eye 1998;12:51-3.

57 Fiacchino F, Grandi L, Soliveri P, et al. Sensitivity to vecuronium after botulinum toxin administration. F Neurosurg Anesthesiol 1997;9:149-53.

58 Truong DD, Cullis PA, O'Brien CF, et al. BotB (botulinum toxin type B): evaluation of safety and tolerability in botulinum toxin type A-resistant cervical dystonia patients (preliminary study). Mov Disord 1997;12:772-5.

59 Mezaki T, Kaji R, Brin MF, et al. Combined use of type A and $\mathrm{F}$ botulinum toxins for blepharospasm: a double-blind controlled trial. Mov Disord 1999;14:1017-20. 